\title{
Mecanismos involucrados en la promoción de crecimiento axonal por la glia envolvente del bulbo olfatorio
}

\begin{abstract}
Vilma C. Muñetón-Gómez ${ }^{1}$, Julián S. Taylor ², Manuel Nieto-Sampedro ${ }^{2}$
1 Laboratorio de Neurociencias, Instituto Nacional de Salud, Bogotá, D.C., Colombia.

2 Instituto Cajal de Neurobiología, CSIC, Madrid, España.

La actividad que promueve el crecimiento de axones por la glia envolvente (GE) del bulbo olfatorio depende de la expresión de diversas moléculas durante el desarrollo, la vida adulta y la reparación de lesiones nerviosas. Diversas moléculas tales como las neurotrofinas y sus receptores, los factores de crecimiento, las moléculas de adhesión celular, las moléculas de matriz extracelular y las moléculas asociadas con la mielinización son producidas por la glia del sistema olfatorio durante el desarrollo. Su expresión sostenida durante la vida adulta parece estar asociada con el reemplazo celular y la alta plasticidad de este sistema. A su vez, su expresión se involucra en procesos de reparación de lesiones mediados por trasplantes de glia. La migración de la GE, que acompaña axones en crecimiento, se observa durante el desarrollo y en procesos de regeneración luego de una lesión. Los trasplantes de.GE permiten la navegación de brotes regenerantes a través del tejido gliótico inhibidor formado luego de una lesión del sistema nervioso central. El propósito de esta revisión es profundizar en los mecanismos de actividad promotora de crecimiento axonal.
\end{abstract}

Palabras clave: glia envolvente, bulbo olfatorio, mielinización, crecimiento axonal.

Mechanisms involved in axonal growth promotion by olfactory bulb ensheathing cells

Neuroplasticity promoted by olfactory ensheathing cells depends on the expression of several molecules during development, adult life and lesion repair. Diverse molecules including neurotrophins and associated receptors, cellular adhesion molecules, extracellular matrix molecules and molecules associated with myelinization are present in the olfactory system during development. Furthermore, their expression continues into adult life and appears to be associated with cellular replacement and the high degree of plasticity of the olfactory system. Olfactory ensheating cell migration, accompanying growing axons, is observed during development, and trasplanted glia cells enable the navigation of regenerating sensory sprouts through inhibitory gliotic tissue formed after lesion of the central nervous system. The purpose of this review is to provide an insight into the neuroregenerative mechanisms and growth promoting properties of these cells.

Key words: glia ensheating cell, olfactory bulbe, myelinization, axonal growth.

Se han realizado muchos esfuerzos con el fin de proveer un ambiente favorable para la regeneración de lesiones en el sistema nervioso central (SNC) $(1,2)$. Una región del sistema nervioso donde hay

\footnotetext{
Correspondencia:

Manuel Nieto-Sampedro

mns@cajal.csic.es
}

Recibido: 21/12/00; aceptado: 30/03/01 recambio celular y plasticidad neural en adultos es el sistema olfatorio, en el que las neuronas olfatorias son continuamente reemplazadas en el adulto por nuevas células originarias del epitelio olfatorio $(3,4)$. Esto ocurre gracias a la glia envolvente (5-7), un tipo de macroglia del sistema olfatorio que guía los axones de neuronas de la mucosa olfatoria hacia sus blancos glomerulares en el bulbo olfatorio (8), lo que ocurre debido a su 
capacidad de unirse a conos de crecimiento, envolver neuritas y migrar con las fibras en crecimiento a través de la zona de transición entre el sistema nervioso central y el periférico (SNC/ SNP) $(9,10)$.

La glia envolvente es miembro de una clase de glia del SNC, denominada aldinoglia (11), que presenta rasgos fenotípicos, inmunocitoquímicos y propiedades promotoras de crecimiento neurítico similares a las células de Schwann (CS). Algunas de las propiedades compartidas proveen una justificación molecular de la capacidad de promover regeneración de fibras del SNC lesionado (11). Así, la expresión común de receptores a factores de crecimiento y receptores a neurotrofinas $(6,12,13)$, la capacidad de migración (14) y de mielinización (15-17), permiten proclamarla como candidata para la reparación de lesiones nerviosas. Al igual que las células de Schwann $(18,19)$, la glia envolvente puede ser cultivada a partir de tejido adulto (11) y purificada en gran escala (14).

La glia envolvente también comparte algunos rasgos fenotípicos con los astrocitos. Entre otros, ambos tipos celulares pertenecen a la glia del SNC, forman parte de la glia limitans del bulbo olfatorio y expresan la proteína ácida fibrilar glial (glial fibrilar acid protein, GFAP) entre sus filamentos intermediarios $(9,20)$. La glia envolvente puede simultáneamente realizar papeles de ambos tipos celulares: astrocitos y células de Schwann cuando se trasplanta en el SNC lesionado (21). A pesar de la similitud entre los astrocitos y las células de Schwann con la glia envolvente, las propiedades inmunocitoquímicas de la glia envolvente son únicas y hacen que la glia constituya un tipo celular único, inclasificable dentro de alguno de los tipos gliales descritos (22). La glia cultivada de bulbo olfatorio de ratas adultas ha sido caracterizada ampliamente $(5,11)$ y algunas de sus características fenotípicas se presentan en la figura 1 y se comparan con las de las CS y los astrocitos en el cuadro 1.

Diversos trabajos han evidenciado la capacidad promotora de regeneración de la glia envolvente en lesiones del sistema nervioso. En un estudio pionero, trasplantes de GE purificada en el asta dorsal medular permitieron la reinervación por axones sensoriales a través de la zona de transición SNC/SNP (7). Variaciones de esta técnica se han probado como terapia de lesiones por rizotomías dorsales múltiples a varios niveles medulares (23-25) en lesiones por transección completa de la médula espinal $(26,27)$ y en lesiones desmielinizantes de la médula espinal (15-17). Varios de estos trabajos in vivo demostraron que los trasplantes de glia envolvente conducen a la recuperación estructural, comportamental y funcional de una amplia gama de lesiones del sistema nervioso central.

A pesar de las grandes evidencias de que la glia envolvente promueve la reparación de lesiones, muchos de sus mecanismos de acción permanecen sin dilucidar. La profundización en los mecanismos de la actividad promotora del crecimiento axonal es el propósito de esta revisión.

\section{Expresión de receptores de factores de crecimiento}

La glia envolvente expresa diversas neurotrofinas y sus receptores, así como moléculas involucradas en la supervivencia neuronal y la regeneración. La glia envolvente expresa el receptor de baja afinidad para el factor de crecimiento nervioso, proteina p75 (nerve growth factor receptor, NGFR-p75) $(6,14)$. Su coexpresión con el receptor de estrógeno alfa $(E R-\alpha)$ involucrado en la activación del factor de transcripción nuclear $\mathrm{NF}-\mathrm{k} \beta$ (nuclear factor-k $\beta$ ), promueve la supervivencia celular (28). La concomitante expresion de $E R \alpha$ y NF-k $\beta$ puede inducir la transcripción de varios genes que confieren rasgos de inmadurez como la conocida expresión de vimentina, epítopes del antígeno $\mathrm{O} 4 \mathrm{y}$ el factor de crecimiento relacionado con la insulina (insulin-like growth factor IGF-1), como también la habilidad de entrar en el ciclo de división celular (29). El recambio celular y la plasticidad neural en adultos en el sistema olfatorio involucra estas moléculas presentes en la GE $(3,4)$.

Otros receptores de neurotrofinas adicionales al NGFR pueden expresarse por la glia envolvente. La similitud molecular entre la GE y las células de Schwann sugiere la expresión de neurotrofinas 

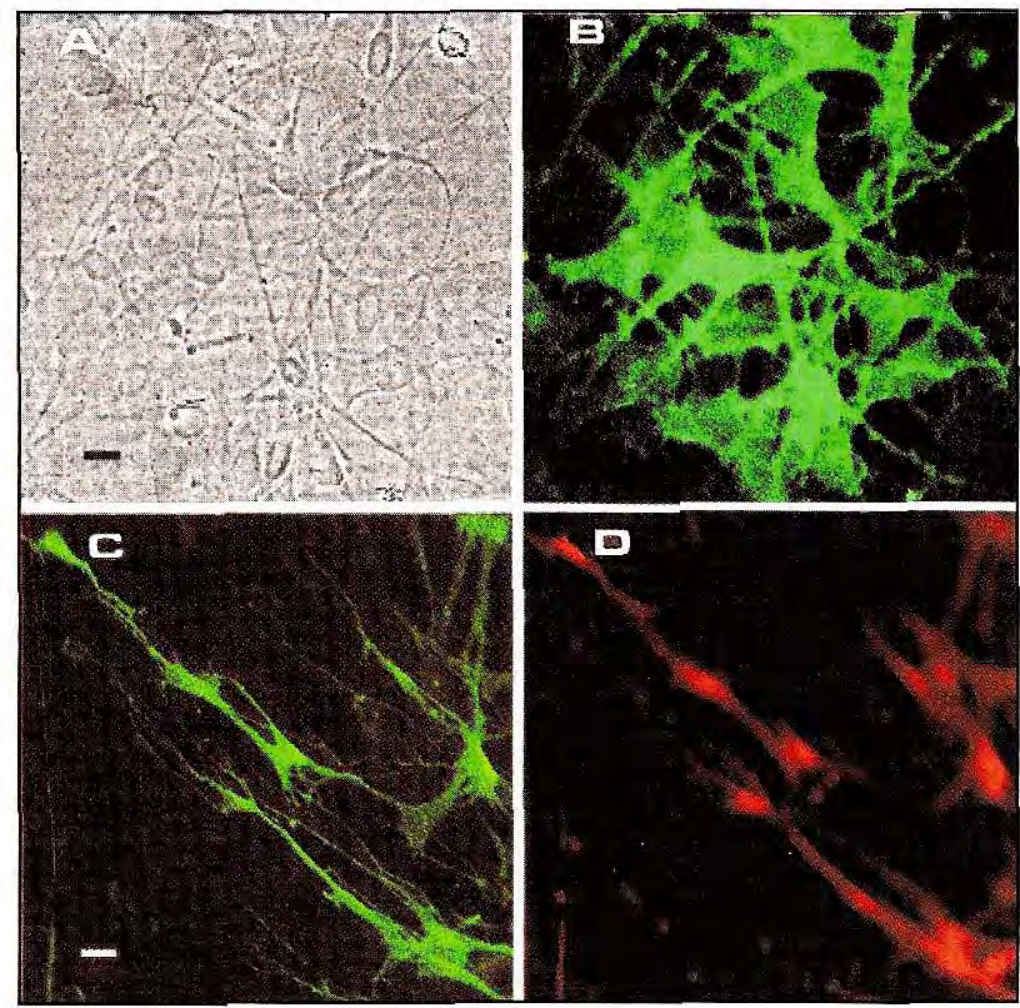

Figura 1. Morfología y propiedades inmunocitoquímicas de la glia envolvente de bulbo olfatorio cultivada a partir de rata adulta.
A, B: cultivo primario después de 10 días in vitro. A. Contraste de fase. B. Inmunorreactividad al receptor p75 NGF.
C, D: cultivo secundario de GE purificada, después de 3 días in vitro.
C. Conservación de la inmunorreactividad al receptor p75 NGF.
D. Inmunorreactividad a la proteína de unión al calcio S-100; barra de calibración: $50 \mu \mathrm{m}$ en A, B y $100 \mu \mathrm{m}$ en C, D.

Cuadro 1. Comparación de algunas características fenotípicas entre la GE, los astrocitos y las CS.

\begin{tabular}{lccc}
\hline Propiedades & Glia envolvente & Astrocitos & Células de Schwann \\
\hline Origen embrionario & Placoda olfatoria & Vesícula cerebral & Cresta neural \\
Contacto axonal & Sí & No & Sí \\
Formación de glia limitans & Sí & Sí & No \\
Formación de lámina basal & No (excepto en glia limitans) & No (excepto en glia limitans) & Sí \\
Migración en el SNC & Sí & Síl & No \\
Receptor del NGF & Sí & No & Sí \\
GFAP & Sí & Sí & Sí \\
GAP-43 & No & No & Sí \\
S-100 & Sí & Sí & Sí \\
N-CAM & Sí & No & Sí \\
O4 & Sí & No & Sí \\
Proteína básica de la mielina & Sí & No & Sí \\
Proteolípido Po & Sí & No determinado & Sí \\
Galactocerebrósido C & Sí & No determinado & Sí \\
\hline
\end{tabular}


y sus receptores por la GE. Las CS expresan formas truncadas de los receptores para neurotrofinas de alta afinidad trkB y trkC que unen el factor neurotrópico derivado de cerebro (brainderived neurotrophin factor, BDNF) y la neurotrofina 4 (neurotrophin 4 NT-4) y la neurotrofina 3 (NT-3), respectivamente. Estas isoformas truncadas carecen de la actividad tirosina cinasa y sitios para la fosforilación de la tirosina encontrados en los receptores con secuencia completa (30). El requerimiento de las neurotrofinas BDNF, NT-4 y NT-3 por parte de las neuronas olfatorias sugiere, igualmente, que son producidas por la glia envolvente. Por ejemplo, las neuronas olfatorias en cultivo dependen de la presencia de estas neurotrofinas para su supervivencia, diferenciación y maduración. Así mismo, durante el desarrollo y después de una remoción del bulbo olfatorio, los axones olfatorios expresan trkB y trkC. Así, sus ligandos BDNF-NT-4 y NT-3 parecen involucrarse en la supervivencia de las neuronas olfatorias regenerantes (31). Como la glia envolvente es el tipo glial que envuelve los axones olfatorios a todo lo largo de su tránsito desde el epitelio olfatorio hasta el glomérulo en el bulbo olfatorio $(8,9,20)$, estas células podrían ser el origen de BDNF, NT4 y NT-3 en el nervio olfatorio.

En conclusión, las evidencias conducen a pensar que la glia envolvente expresa varias neurotrofinas y sus receptores, entre las cuales están el NGF, BDNF, NT-4 y NT-3. Estas moléculas podrían ser parcialmente responsables de la alta plasticidad en el sistema olfatorio y en los procesos regenerativos mediados por trasplantes de GE.

\section{Moléculas en la membrana plasmática}

Diversas moléculas de adhesión neural (cell adhesion molecules, CAM) están presentes en la membrana de la GE y actúan como potentes promotores de crecimiento axonal. La molécula de adhesión neuroglial L1 (Ng CAM-L1) se ha detectado en haces de nervios olfatorios del bulbo olfatorio (32) y en procesos axonales de neuronas sensoriales en contacto con la GE en cultivos de neuroepitelio olfatorio (33). Otras moléculas como la CAM-neural y la forma embrionaria con alto contenido en ácido polisiálico (CAM-E) se expresan en la membrana plasmática de la GE que contribuye a la formación de la glia limitans y en la capa de fibras nerviosas olfatorias durante el desarrollo y la vida adulta $(34,35)$. La expresión de estas moléculas establece contactos entre fascículos de axones y entre estos fascículos y la GE. La retención en la expresión de estas moléculas embrionarias durante la vida adulta en el sistema olfatorio parece asociarse al recambio celular y la alta plasticidad de este sistema.

\section{Mioléculas en la matriz extracelular}

La actividad promotora de crecimiento axonal por parte de la GE depende de un balance relativo entre factores de atracción y repulsión. Por un lado, la GE produce moléculas de matriz extracelular que estimulan la adopción de un fenotipo atrayente y promotor de crecimiento neurítico. Por otro lado, la GE responde dinámicamente a cambios en la composición de la matriz extracelular, con el fin de confinar el crecimiento de axones a una vía con especificidad por su blanco.

En la adopción de un fenotipo atrayente y promotor de crecimiento neurítico, la GE secreta laminina, un potente promotor de crecimiento axónico, altamente expresado por la GE en el período de máximo crecimiento axonal de la vía nerviosa olfatoria durante el desarrollo (36) y en la etapa postnatal de roedores (37). Adicionalmente, cultivos secundarios de GE de ratas adultas (5) y cultivos de la línea celular de GE NOBEC-1 (38) expresan laminina. La acción de la laminina podría llevarse a cabo por una adhesión débil de axones al sustrato celular (36), mediada por receptores integrinas que contienen la subunidad $\beta-1$ (39) o por una adhesión fuerte, reforzada por la presencia de galectina-1, una lectina ligadora de lactosa expresada por la GE (40). También, el heparán sulfato proteoglicano (HSPG), un modulador de neuritogénesis, es expresado por la glia envolvente (38). El HSPG juega el papel de inductor de la actividad estimulante de crecimiento axonal del factor de crecimiento fibroblástico (FGF-1), presente en el nervio olfatorio (41). HSPG y FGF1 actúan conjuntamente mediante la modulación en la producción de laminina y galectina por la GE. De esta manera, se han evidenciado patrones de expresión similares tanto a HSPG como a laminina en la GE que migra junto con los axones 
de neuronas olfatorias sensoriales en el desarrollo de la vía nerviosa olfatoria. Estas moléculas proveen un sustrato neuritogénico conductivo para axones en crecimiento (36).

En relación con los cambios en la composición de la MEC, la GE responde dinámicamente con el fin de confinar el crecimiento de axones a una vía con especificidad para su blanco. La expresión de algunos inhibidores de crecimiento neurítico en la matriz extracelular modulan las propiedades promotoras de neuritogénesis de la GE. Tal es el caso del condroitín sulfato proteoglicano (chondroitin sulphate proteoglycan, CSPG) identificado durante el desarrollo en la lámina basal del telencéfalo y sobre cada lado de los haces de fibras nerviosas del bulbo olfatorio en formación (41). Adicionalmente, los fascículos de axones olfatorios penetran a través de orificios negativos a la molécula quimiorrepulsora semaforina $3 \mathrm{~A}$ en el mesénquima subyacente a la lámina cribosa. Así, la semaforina 3A delimita y conduce los haces nerviosos que finalmente invaden las porciones profundas del bulbo olfatorio (42). Hallazgos similares en ensayos in vitro demostraron que la GE responde activamente a moléculas en la matriz extracelular. En tales ensayos, la GE plaqueada sobre cubreobjetos cubiertos con matrigel y laminina adoptó una morfología ahusada (spindle shaped) con extensión de largos procesos celulares, una adecuada adhesión y una alta capacidad de migración en contraste con la mínima extensión, migración y forma ovoide que exhiben las células en cultivos sobre poli-L-lisina y sobre condroitín sulfato proteoglicano. No obstante, las neuritas emergentes de cultivos de explantes de neuroepitelio olfatorio, plaqueados sobre diferentes sustratos, crecieron preferencialmente sobre la superficie de la GE más que sobre la matriz subyacente (43). Adicionalmente, la GE interactuó con las moléculas de la matriz al ser suspendida en el colágeno o matrigel que rellenaba los tubos de silicona, los cuales se implantaron en el nervio ciático (44) y en el hipocampo (45) y promovieron la regeneración nerviosa y la reinervación distal en el sistema nervioso periférico y en el central, respectivamente.
En conclusion, las moléculas promotoras de crecimiento como laminina, HSPG, FGF-1 y galectina-1 producidas por la GE han de estar en un balance relativo con otras moléculas confinadoras del crecimiento axonal para proporcionar un sustrato celular conductor y promotor de crecimiento de neuritas.

\section{Capacidad de migración de la glia envolvente}

La giia envolvente cuenta con una alta capacidad migratoria en el SNC. Tanto en el SNC no lesionado como en el lesionado experimentalmente, la GE ha demostrado sobrevivir, migrar e interactuar con el tejido subyacente en pro del crecimiento axonal y la navegación de estos axones hacia su blanco específico.

La glia envolvente sobrevivió y migró al ser trasplantada en varias regiones del cerebro no lesionado. Cuando la GE se trasplantó en el hipocampo, se encontró intercalada entre células de la capa piramidal y granular dentada y en la fisura del hipocampo. Estas células migraron al tercer ventrículo, el acueducto, la sustancia negra, el núcleo arciforme del hipotálamo y la cápsula interna (14). Igualmente, la glia acompañó los axones en crecimento después de realizar injertos o trasplantes en el SNC. Se observó que los axones y la glia olfatoria crecieron a partir de injertos de mucosa olfatoria ubicados en el cuarto ventrículo (46) y la corteza parietal (47) de ratones neonatos.

En lesiones experimentales, se ha confirmado la capacidad de supervivencia y migración de la glia envolvente. Por ejemplo, la GE implantada en una matriz de colágeno, sobrevivió a nivel de la vía fimbria-fórnix, transectada unilateralmente. A pesar de que la glia no migró hacia el parénquima neural adyacente, si promovió la entrada de axones colinérgicos septales inmunorreactivos a acetilcolinesterasa y a la proteína asociada con crecimiento (growth associated protein GAP 43) (45). Por otro lado, la glia envolvente trasplantada en modelos de lesiones medulares muestra una alta capacidad de migración. Por ejemplo, se observó su migración desde el punto de inyección en los segmentos cervicales C7 y C8, luego de ser trasplantada tras lesión por rizotomía dorsal del plexo braquial (segmentos C4-T2). La glia migró 
hasta las láminas I y II del asta dorsal, hacia el epéndima (lámina $X$ ) y hacia la entrada de la raíz dorsal. A este nivel, las fibras sensoriales regeneraron y se localizaron adyacentes a la GE en las láminas donde se proyectan normalmente $(35,36)$. En otro estudio, la GE fue capaz de migrar largas distancias en la columna dorsal de la médula espinal de ratas al ser trasplantada, luego de una lesión desmielinizante por radiación con rayos $\mathrm{X}$ y bromuro de etidio a nivel del segmento toráxico T10 (16). Adicionalmente, las células de GE trasplantadas entre los segmentos cervicales C1 y C2, después de una lesión eléctrica del tracto corticoespinal (corticospinal tract, CST), se extendieron en las vecindades del tracto. Así, la migración caudal alcanzó distancias de $5 \mathrm{~mm}$ entre las tres y cuatro semanas, hasta llegar a poco más de $10 \mathrm{~mm}$ a los tres meses (17). Por otra parte, la GE trasplantada luego de una transección completa de la médula, migró desde los sitios de inyección en ambos muñones del segmento toráxico T8, a través de la sustancia blanca y gris, tanto rostral como caudalmente (26).

La similitud entre la glia envolvente y las células de Schwann incluye la expresión de p75 NGFR. Existe una correlación temporal entre la migración de las células de Schwann y el aumento en la expresión de NGF/NGFR durante el desarrollo y denervación periférica. Estas moléculas promueven la migración de las CS $(12,13)$ y, probablemente , la de la GE. Por ejemplo, en cocultivos de glia envolvente y neuronas del epitelio olfatorio, la expresión de NGFR se mantiene en la membrana plasmática glial y en la neurita, exceptuando la porción de la membrana glial en contacto directo con la neurita del epitelio olfatorio (6). La subregulación del NGFR por contacto axonal también ha sido informada para las CS y se postula que gradientes de NGF o del NGFR pueden guiar su migración. Así, el pretratamiento con NGF de secciones nerviosas denervadas incrementa la velocidad de migración de las CS. Este incremento se revierte con el uso de anticuerpos contra el NGF y el NGFR. Puesto que esta estrategia metodológica satura los sitios de unión al NGF, lo cual resulta en un gradiente de sustrato NGF que dirige la migración celular (12), es posible que gradientes de NGF en el cerebro puedan guiar la migración de la GE. No obstante, no existen evidencias directas que soporten esta hipótesis (14). Se ha informado que el NGF incrementa la expresión de Ng NCAM L1 en cultivos de CS, lo que indica que la regulación de moléculas de adhesión celular puede ser uno de los mecanismos a través de los cuales el NGF podría controlar la migración celular de las CS (48). Como la glia envolvente expresa tanto el receptor para el NGF como la molécula de adhesión Ng NCAM L1, es posible que un mecanismo similar al descrito para las CS regule le migración de la GE.

Diferencias locales en distintas regiones del SNC parecen influir en la migración y en la capacidad reparadora de lesiones de la glia envolvente trasplantada. Así, en presencia de GE viable y funcionalmente activa, axones de neuronas internucleares del núcleo abducens fueron incapaces de cruzar a través del fascículo longitudinal medial (medial longitudinal fascicle, MLF) transectado, sin llegar a proyectarse normalmente al núcleo oculomotor. A este nivel, la GE migró preferencialmente hacia los somas celulares del abducens, en dirección opuesta a su blanco en el núcleo oculomotor. Es posible que la regeneración sea promovida por la GE solamente cuando la dirección de migración coincide con la dirección de los brotes axónicos regenerantes (49). Este requerimiento puede relacionarse con el modo de acción de las células de Schwann, las cuales se organizan en cordones rodeados por lámina basal (bandas de Büngner) que guían los axones hacia su blanco (50). Así, podría requerirse una disposición especial de la GE que marcara el camino de los brotes regenerantes. También se conoce que el NGFR se expresa en el tejido blanco. Así, existe la posibilidad que 775 pueda dirigir la morfología y organización axonal in situ(13), así como la de la GE que los acompaña.

Ya que la glia envolvente migra acompañando axones en crecimiento, sus preferencias migratorias en adultos han de ser bien definidas. De esta manera, podría utilizarse como una estrategia general para promover la reparación de lesiones del sistema nervioso central (14). 


\section{Interacción de la glia envolvente trasplantada con otros tipos celulares}

El mayor obstáculo para la regeneración axonal en el SNC después de una lesión es la presencia de la cicatriz glial, la cual está formada, predominantemente, por astrocitos y microglia $(51,52)$. La GE interacciona con astrocitos y es capaz de suprimir la producción de la cicatriz glial en lesiones del sistema nervioso central adulto. En los ensayos mencionados, los trasplantes de GE suprimieron la aparición de la gran hipertrofia astrocítica que se encuentra típicamente después de realizar lesiones eléctricas del haz corticoespinal (CST) en médulas sin trasplantar (17). Adicionalmente, la GE se encontró mezclada con células GFAP fuertemente positivas, presentes en la cicatriz glial formada luego de una transección completa de la médula, lo cual indica que el tejido gliótico no ejerce una influencia inhibitoria sobre la migración (26). Por otra parte, la gliosis reactiva en la base de la cavidad transectada a nivel de la vía fimbria-fórnix presentó células GFAP positivas que extendieron pocos procesos hacia los injertos de glia envolvente. En todos estos casos, la glia envolvente mantuvo axones en crecimiento aislados del ambiente gliótico inhibidor.

La glia envolvente interacciona con otros tipos celulares. Así, la GE trasplantada, luego de una transección completa de la médula espinal, rodeó los axones regenerantes del tracto corticoespinal (CST) y viajó sobre la meninge de la superficie ventral medular, lo cual indica que la población de células piales podría contribuir al ambiente promotor de neuritogénesis (26). Adicionalmente, la GE es altamente angiogénica e induce a la formación de un denso plexo de microvasos en el CST al ser trasplantada tras una lesión eléctrica (17). Con relación a estos hallazgos, los trasplantes de GE presentan una alta asociación con células del epitelio coroideo y células endoteliales de vasos sanguínos en el cerebro no lesionado, por lo cual se postula que estas últimas puedan ser una vía para la migración de la GE (14).

\section{Capacidad de mielinización de la glia envolvente}

La capacidad de interacción entre la GE y las neuronas y la presencia de moléculas asociadas a la mielinización se ha estudiado in vitro, in situ e in vivo. Moléculas como la glicoproteína Po, epítopes reconocidos por el anticuerpo O4, el galactocerebrósido $\mathrm{C}(\mathrm{Gal} \mathrm{C})$ y la proteína básica de la mielina (protein basic myelin, PBM), son expresadas en forma variable in vitro. En la presencia de análogos del AMPc, los cultivos de GE de rata E18 ocasionalmente expresaron $\mathrm{Gal}$ C y no expresaron PBM (53). Bajo condiciones similares, cultivos de rata P3 no expresaron Po, Gal C, ni PBM $(35,54)$. En contraste con estos hallazgos, los cultivos secundarios de GE obtenida a partir de rata adulta expresan PBM en ausencia de análogos del AMPc (5). Otros ensayos in vitro realizados en presencia de neuronas evidencian la capacidad de mielinización. Así, en cocultivos de GE y neuronas del ganglio de la raíz dorsal (dorsal root ganglia, DRG) de embriones de rata, series contiguas de glia ahusada se alinearon a lo largo de las neuritas, envolviendo varias de ellas sin mielinizar o envolviendo y mielinizando sólo una neurita. También, la GE pudo ensamblar lámina basal y expresar moléculas indicadoras de mielinización, Gal C y PBM (55). Además, la GE adulta cultivada simultáneamente con neuronas de DRG (29) y con neuronas de neuroepitelio embrionario (6) envolvió neuritas individuales. Por otra parte, estudios in situ han demostrado que la GE en adultos no envuelve axones individuales pero sí fascículos de axones densamente empaquetados. Se identificó lámina basal rodeando fascículos nerviosos en la GE, lo que contribuye a formar la glia limitante pero, raras veces, en células de GE individuales (20).

Estudios que utilizan modelos de lesiones muestran resultados particulares. Así, en estudios in vivo, R. Franklin y colaboradores (15) demostraron que los trasplantes de la línea celular tsT ONEC - una línea que exhibe características similares a la GE de cultivos de rata P7 - (35), remielinizaron el funículo dorsal de la médula espinal, previamente lesionada con rayos $\mathrm{X} y$ bromuro de etidio, en ratas adultas. Estas células presentaron lámina basal y solamente mielinizaron axones individuales, los cuales estaban rodeados por vainas de mielina que expresaron alto contenido en la glicoproteína específica de mielina periférica P0. Así mismo, algunas células 
envuelven axones de pequeño diámetro sin formar vainas de mielina compacta (15). Utilizando el mismo modelo de lesión medular y trasplantes de homogenizado de la capa de fibras nerviosas de bulbos olfatorios de ratas neonatales, Imaizumi y colaboradores describieron resultados morfológicos similares y desmostraron que la mielinización retornaba los potenciales de acción y la velocidad de conducción de los axones a valores normales (16). Igualmente, Y. Li y colaboradores encontraron un fenotipo mielinizante similar al descrito y positivo a P0, al trasplantar GE proveniente de cultivos primarios de ONGL de ratas adultas en animales con lesiones producidas por corrientes eléctricas realizadas en el tracto corticoespinal (cortico spinal tract, CST) de la médula espinal (17). El punto de reentrada caudal de los axones desde el trasplante al CST presentó una mezcla de mielina central y periférica, lo cual se identificó por el inmunomarcaje positivo a PO y a la glicoproteína de mielina oligodendrocítica (myelin oligodendrocyte glycoprotein, MOG) y por la reanudación de la mielinización central (17). Es importante resaltar que Imaizumi, 1998, y Li, 1998, trasplantaron tanto homogenizados como células de cultivos de bulbo olfatorio de ratas adultas sin previa purificación de la GE. Estos trasplantes contienen otros tipos celulares como microglia, células endoteliales y astrocitos. La contribución de cada tipo celular trasplantado y de los presentes en el sitio de lesión requiere mayor análisis.

En conclusión, el hallazgo de varias moléculas características de un fenotipo mielinizante in vitro e in situ por la glia envolvente y la expresión de $\mathrm{PO}$ en la remielinización posterior a la lesión mediada por trasplantes de GE, se asemeja a la mielinización periférica producida por las células de Schwann.

\section{Conclusiones}

Algunos de los mecanismos de acción por los cuales la glia envolvente promueve la reparación de lesiones incluye la expresión de varias neurotrofinas y sus receptores, entre los cuales están el NGF, BDNF, NT-3 y NT-4. La continua expresión de estas moléculas y de moléculas de adhesión neural podría ser parcialmente responsable de la plasticidad en el sistema olfatorio y de los procesos regenerativos mediados por trasplantes de GE.

La actividad promotora de crecimiento axonal por parte de la GE depende también de un balance relativo de moléculas promotoras de crecimiento, como la laminina, HSPG, FGF-1 y galectina-1, con otras moléculas repulsoras del crecimiento axonal como semaforina 3A y CSPG. Este balance proporciona un sustrato celular conductor de axones con especificidad por su blanco.

Experimentalmente, la glia envolvente ha demostrado sobrevivir, migrar e interactuar con el tejido subyacente tanto en el SNC no lesionado como en el lesionado. La GE migra interactuando con astrocitos y otros tipos celulares. Además, la glia envolvente acompaña axones en crecimiento y los mantiene aislados del ambiente inhibidor de la cicatriz glial. La migración parece ser regulada por el receptor para el NGF y la expresión de moléculas de adhesión celular a través de un mecanismo similar al propuesto para las células de Schwann. Por último, la mielinización por parte de la GE se asemeja fenotípicamente a la mielinización periférica producida por las CS.

Gracias a las características propias, como a las compartidas con las células de Schwann, los trasplantes de glia envolvente han conducido a una recuperación estructural y funcional de diversos tipos de lesiones tanto en el SNC como en el SNP. Es de vital importancia definir los mecanismos de acción y su contribución para proveer un ambiente íavorable para la regeneración. De esta manera, podría utilizarse como una estrategia general para promover la reparación de lesiones del sistema nervioso.

\section{Agradecimientos}

Queremos dar gracias al Instituto Nacional de Salud, a Colciencias y al programa de científicos y tecnólogos extranjeros de España por apoyar la participación de Vilma Muñetón-Gómez en los estudios para la promoción de la regeneración y la plasticidad neural en el sistema nervioso central efectuados en el Instituto Cajal de Neurociencias, Madrid.

El soporte financiero para algunas de las investigaciones en curso ha sido aportado por la 
Comunidad Económica Europea (Biomed II Contracto BMH4-97-2586) y el Ministerio de Sanidad español (FIS 98/0830).

\section{Referencias}

1. Behar O, Mizuno K, Neumann S, Woolf CJ. Putting the spinal cord together again. Neuron 2000;26:291-3.

2. Qiu J, Cai D, Filbin MT. Glial inhibition of nerve regeneration in the mature mammalian CNS. Glia 2000; 29:166-74.

3. Graziadei PP, Levine RR, Graziadei GA. Regeneration of olfactory axons and synapse formation in the forebrain after bulbectomy in neonatal mice. Proc Natl Acad Sci USA 1978;75:5230-4.

4. Graziadei PP, Graziadei GA. Neurogenesis and neuron regeneration in the olfactory system of mammals. I. Morphological aspects of differentiation and structural organization of the olfactory sensory neurons. J Neurocytol 1979;8:1-18.

5. Ramón-Cueto A, Nieto-Sampedro M. Glial cells from adult rat olfactory bulb: immunocytochemical properties of pure cultures of ensheathing cells. Neuroscience 1992;47:213-20.

6. Ramón-Cueto A, Pérez J, Nieto-Sampedro M. In vitro enfolding of olfactory neurites by 755 NGF receptor positive ensheathing cells from adult rat olfactory bulb. Eur J Neurosci 1993;5:1172-80.

7. Ramón-Cueto A, Nieto-Sampedro M. Regeneration into the spinal cord of transected dorsal root axons is promoted by ensheathing glia transplants. Exp Neurol 1994; 127:232-44.

8. Doucette JR. The glial cells in the nerve fiber layer of the rat olfactory bulb. Anat Rec 1984;210:385-91.

9. Doucette R. Glial influences on axonal growth in the primary olfactory system. Glia 1990;3:433-49.

10. Fraher JP. The transitional zone and CNS regeneration [corrected and republished article originally printed in $\mathrm{J}$ Anat 1999 feb;194(Pt 2):161-82]. J Anat 2000;196(Pt 1):137-58.

11. Gudino-Cabrera G, Nieto-Sampedro M. Estrogen receptor immunoreactivity in Schwann-like brain macroglia. J Neurobiol 1999;40:458-70.

12. Anton ES, Weskamp G, Reichardt LF, Matthew WD. Nerve growth factor and its low-affinity receptor promote Schwann cell migration. Proc Natl Acad Sci USA 1994;91:2795-9.

13. Bentley CA, Lee KF. p75 is important for axon growth and Schwann cell migration during development. $J$ Neurosci 2000;20:7706-15.

14. Gudino-Cabrera G, Nieto-Sampedro M. Ensheathing cells: large purification from adult olfactory bulb, freezepreservation and migration of trasplanted cells in adult brain. Rest Neuro Neurosc 1996;10:25-34.
15. Franklin RJ, Gilson JM, Franceschini IA, Barnett SC. Schwann cell-like myelination following transplantation of an olfactory bulb-ensheathing cell line into areas of demyelination in the adult CNS. Glia 1996;17: 217-24.

16. Imaizumi T, Lankford KL, Waxman SG, Greer CA, Kocsis JD. Transplanted olfactory ensheathing cells remyelinate and enhance axonal conduction in the demyelinated dorsal columns of the rat spinal cord. $\mathrm{J}$ Neurosci 1998;18:6176-85.

17. Li Y, Field PM, Raisman G. Regeneration of adult rat corticospinal axons induced by transplanted olfactory ensheathing cells. J Neurosci 1998;18:10514-24.

18. Muñetón VC, Garavito ZV, Hurtado H. Cultivo de células de Schwann, un modelo del microambiente del sistema nervioso. Biomédica 1998;18:45-54.

19. Garavito ZV, Sutachán JJ, Muñetón VC, Hurtado H. Is $\mathrm{S}-100$ protein a suitable marker for adult Schwann cells? [letter]. In Vitro Cell Dev Biol Anim 2000;36:281-3.

20. Barber PC, Lindsay RM. Schwann cells of the olfactory nerves contain glial fibrillary acidic protein and resemble astrocytes. Neuroscience 1982;7:3077-90.

21. Doucette R. Olfactory ensheathing cells: potential for glial cell transplantation into areas of CNS injury. Histol Histopathol 1995;10:503-7.

22. Ramón-Cueto A, Valverde F. Olfactory bulb ensheathing glia: a unique cell type with axonal growthpromoting properties. Glia 1995;14:163-73.

23. Muñetón-Gómez VC, Taylor JS, Nieto-Sampedro M. Rizotomía multiple del plexo braquial: tipos de axones regenerados en la médula espinal y su relación con la glía envolvente trasplantada. Rev Neurol 1999;30:284.

24. Taylor JS, Muñetón-Gómez VC, Nieto-Sampedro M. Reparación funcional del sistema sensorial tras rizotomía del plexo braquial mediada por trasplantes de glía envolvente. Rev Neurol 1999;30:256.

25. Navarro X, Valero A, Gudino G, et al. Ensheathing glia transplants promote dorsal root regeneration and spinal reflex restitution after multiple lumbar rhizotomy. Ann Neurol 1999;45:207-15.

26. Ramón-Cueto A, Cordero MI, Santos-Benito FF, Avila J. Functional recovery of paraplegic rats and motor axon regeneration in their spinal cords by olfactory ensheathing glia. Neuron 2000;25:425-35.

27. Ramón-Cueto A, Plant GW, Avila J, Bunge MB. Longdistance axonal regeneration in the transected adult rat spinal cord is promoted by olfactory ensheathing glia transplants. J Neurosci 1998;18:3803-15.

28. Carter BD, Kaltschmidt C, Kaltschmidt B, et al. Selective activation of NF-kappa B by nerve growth factor through the neurotrophin receptor p75. Science 1996; 272:542-5.

29. Gudino-Cabrera G, Nieto-Sampedro M. Schwann-like macroglia in adult rat brain. Glia 2000;30:49-63. 
30. Valenzuela DM, Maisonpierre PC, Glass DJ, et al. Alternative forms of rat TrkC with different functional capabilities. Neuron 1993;10:963-74.

31. Roskams AJ, Bethel MA, Hurt KJ, Ronnett GV. Sequential expression of Trks $A, B$, and $C$ in the regenerating olfactory neuroepithelium. J Neurosci 1996; 16:1294-1307.

32. Miragall F, Kadmon G, Schachner M. Expression of L1 and N-CAM cell adhesion molecules during development of the mouse olfactory system. Dev Biol 1989;135:27286.

33. Pixley SK. Characterization of olfactory receptor neurons and other cell types in dissociated rat olfactory cell cultures. Int J Dev Neurosci 1996;14:823-39.

34. Miragall F, Kadmon G, Husmann M, Schachner M. Expression of cell adhesion molecules in the olfactory system of the adult mouse: presence of the embryonic form of N-CAM. Dev Biol 1988;129:516-31.

35. Franceschini IA, Barnett SC. Low-affinity NGF-receptor and $\mathrm{E}-\mathrm{N}-\mathrm{CAM}$ expression define two types of olfactory nerve ensheathing cells that share a common lineage [published erratum appears in Dev Biol 1996;25;176:149]. Dev Biol 1996;173:327-43.

36. Treloar HB, Nurcombe V, Key B. Expression of extracellular matrix molecules in the embryonic rat olfactory pathway. J Neurobiol 1996;31:41-55.

37. Liesi P. Laminin-immunoreactive glia distinguish regenerative adult $\mathrm{CNS}$ systems from non-regenerative ones. EMBO J 1985;4:2505-11.

38. Goodman MN, Silver J, Jacobberger JW. Establishment and neurite outgrowth properties of neonatal and adult rat olfactory bulb glial cell lines. Brain Res 1993;619:199213.

39. Venstrom KA, Reichardt LF. Extracellular matrix. 2: Role of extracellular matrix molecules and their receptors in the nervous system. FASEB J 1993;7:996-1003.

40. St John JA, Key B. Expression of galectin-1 in the olfactory nerve pathway of rat. Brain Res Dev 1999;117: 171-8.

41. Key B, Treloar HB, Wangerek L, Ford MD, Nurcombe V. Expression and localization of FGF-1 in the developing rat olfactory system. J Comp Neurol 1996;366:197-206.

42. Giger RJ, Wolfer DP, De Wit GM, Verhaagen J. Anatomy of rat semaphorin III/collapsin-1 mRNA expression and relationship to developing nerve tracts during neuroembryogenesis. J Comp Neurol 1996;375:378-92.

43. Tisay KT, Key B. The extracellular matrix modulates olfactory neurite outgrowth on ensheathing cells. J Neurosci 1999;19:9890-9.

44. Verdu E, Navarro X, Gudino-Cabrera G, et al. Olfactory bulb ensheathing cells enhance peripheral nerve regeneration. Neuroreport 1999;10:1097-101.

45. Smale KA, Doucette R, Kawaja MD. Implantation of olfactory ensheathing cells in the adult rat brain following fimbria-fornix transection. Exp Neurol 1996;137:225-33.

46. Morrison EE, Graziadei PP. Transplants of olfactory mucosa in the rat brain I. A light microscopic study of transplant organization. Brain Res 1983;279:241-5.

47. Monti GA, Morrison EE. Experimental studies on the olfactory marker protein. IV. Olfactory marker protein in the olfactory neurons transplanted within the brain. Brain Res 1988;455:401-6.

48. Assouline JG, Pantazis NJ. Localization of the nerve growth factor receptor on fetal human Schwann cells in culture. Exp Cell Res 1989;182:499-512.

49. Gudino-Cabrera G, Pastor AM, de la Cruz RR, Delgado-García JM, Nieto-Sampedro M. Limits to the capacity of transplants of olfactory glia to promote axonal regrowth in the CNS. Neuroreport 2000;11:467-71.

50. Ramón Y, Cajal S. Cajal's degeneration and regeneration of the nervous system. New York: Oxford University Press; 1991.

51. Bovolenta P, Wandosell F, Nieto-Sampedro M. CNS glial scar tissue: a source of molecules which inhibit central neurite outgrowth. Prog Brain Res 1992;94:367-79.

52. Fernaud-Espinosa I, Nieto-Sampedro M, Bovolenta P. A neurite outgrowth-inhibitory proteoglycan expressed during development is similar to that isolated from adult brain after isomorphic injury. J Neurobiol 1998;36:16-29.

53. Doucette R, Devon R. Elevated intracellular levels of cAMP induce olfactory ensheathing cells to express GALC and GFAP but not MBP. Glia 1995;13:130-40.

54. Barnett SC, Hutchins AM, Noble M. Purification of olfactory nerve ensheathing cells from the olfactory bulb. Dev Biol 1993;155:337-50.

55. Devon R, Doucette R. Olfactory ensheathing cells myelinate dorsal root ganglion neurites. Brain Res 1992;589:175-9. 